\title{
Endoscopic Mucosal Resection with Circumferential Mucosal Incision for Colorectal Neoplasms: Comparison with Endoscopic Submucosal Dissection and between Two Endoscopists with Different Experiences
}

\author{
Dong-Hoon Yang ${ }^{1}$, Min-Seob Kwak', Sang Hyoung Park ${ }^{1}$, Byong Duk Ye ${ }^{1}$, Jeong-Sik Byeon ${ }^{1}$, Seung-Jae Myung ${ }^{1}$, Suk-Kyun Yang ${ }^{1}$, \\ Hyun Gun Kim ${ }^{2}$ and Shai Friedland ${ }^{3}$ \\ ${ }^{1}$ Department of Gastroenterology, Asan Medical Center, University of Ulsan College of Medicine, Seoul, ${ }^{2}$ Institute for Digestive Research, \\ Soonchunhyang University College of Medicine, Seoul, Korea, ${ }^{3}$ Department of Gastroenterology and Hepatology, Stanford University School \\ of Medicine, Stanford, Department of Gastroenterology, VA Palo Alto Health Care System, Palo Alto, CA, USA
}

Background/Aims: Endoscopic mucosal resection with circumferential mucosal incision (CMI-EMR) may offer benefits comparable to those of endoscopic submucosal dissection (ESD), while requiring less technical proficiency than ESD.

Methods: We retrospectively compared the outcomes of CMI-EMR $(n=34)$ and size-matched ESD $(n=102)$, which were performed by a Korean endoscopist for colorectal epithelial lesions of 20-35 mm. Procedural parameters of CMI-EMRs performed by an American ESD novice $(n=30)$ were compared with those performed by the Korean endoscopist.

Results: The lesion size was $22.3 \pm 3.9 \mathrm{~mm}$ and $22.9 \pm 2.4 \mathrm{~mm}$ in the CMI-EMR and size-matched ESD groups, respectively $(p=0.730)$. The resection time was $12.7 \pm 7.0$ minutes in the CMI-EMR group and $45.6 \pm 30.1$ minutes in the ESD group $(p<0.001)$. The en bloc resection rate was $94.1 \%$ in the CMI-EMR group and $100 \%$ in the ESD group $(p=0.061)$. There were no differences in the en bloc resection and complication rates of CMI-EMRs between a Korean and an American endoscopist.

Conclusions: For the treatment of moderate-size colorectal lesions, CMI-EMR showed a trend toward lower en bloc resection rate, but required shorter procedure time than ESD. CMI-EMR outcomes were similar when performed by a Korean ESD expert and an American ESD novice. Clin Endosc 2017;50:379-387

Key Words: Neoplasms; Colon; Rectum; Endoscopic mucosal resection; Endoscopic submucosal dissection

\section{INTRODUCTION}

Compared with conventional endoscopic mucosal resection

Received: April 20, 2016 Revised: January 22, 2017

Accepted: January 25, 2017

Co-correspondence: Dong-Hoon Yang

Department of Gastroenterology, Asan Medical Center, University of Ulsan College of Medicine, 88 Olympic-ro 43-gil, Songpa-gu, Seoul 05505, Korea Tel: +82-2-3010-5809, Fax: +82-2-3010-6517, E-mail: dhyang@amc.seoul.kr

Shai Friedland

Department of Gastroenterology, VA Palo Alto Health Care System, 3801 Miranda Ave, Palo Alto, CA 94304, USA

Tel: +1-650-493-5000, x64800 Fax: +1-650-498-6323, E-mail: shai_friedland@yahoo.com

(cc) This is an Open Access article distributed under the terms of the Creative Commons Attribution Non-Commercial License (http://creativecommons.org/ licenses/by-nc/3.0) which permits unrestricted non-commercial use, distribution, and reproduction in any medium, provided the original work is properly cited.
(EMR), endoscopic submucosal dissection (ESD) can achieve higher en bloc resection rates and lower recurrence rates. ${ }^{1-3}$ ESD is considered the standard treatment of large, non-pedunculated, colorectal adenomas and early adenocarcinomas in Japan and some centers in Korea. ${ }^{4-6}$ Given that the primary goal of endoscopic resection for colorectal neoplasia is to prevent colorectal cancer and reduce cancer-related mortality, en bloc resection is preferred, when feasible, to maximize the accuracy of the histologic assessment and to reduce the risk of local recurrence from incomplete excision, using piecemeal methods. Although ESD allows for en bloc resection of large colorectal lesions, it has several disadvantages compared to piecemeal EMR, including prolonged procedure time, technical difficulty, high risk of perforation, and the need for 
extended, in-hospital postoperative observation. In countries other than Japan, including the United States, colorectal ESD is rarely performed, and although it is becoming increasingly popular in Korea, it has not achieved universal acceptance.

Circumferential mucosal incision (CMI) followed by snare resection was first introduced by Japanese endoscopists to improve the en bloc resection rate of gastric epithelial neoplasms in 1988. This technique, often called endoscopic mucosal resection with circumferential mucosal incision (CMI-EMR, precut EMR), was designed to improve the en bloc resection rate of early neoplasms of the esophagus and stomach, where grasping flat lesions with a standard snare is often difficult. Its usefulness for early gastric cancers $<20 \mathrm{~mm}$ in size and small rectal carcinoid tumors is well established. ${ }^{8-11}$ Recently, some Japanese and Korean studies reported that CMI-EMR could achieve a $65.2 \%-67 \%$ en bloc resection rate for large colorectal neoplasms with perforation rates of $0 \%-6.3 \% .{ }^{12-14}$ However, little is known about the efficacy and safety of CMIEMR for large colorectal epithelial neoplasms, relative to ESD. Moreover, no data on CMI-EMR are available from Western centers with limited ESD experience.

We aimed to compare the efficacy of CMI-EMR and ESD as a treatment of large colorectal epithelial neoplasia by analyz- ing data from a Korean endoscopist with extensive experience in $\mathrm{ESD}^{15}$ and a Western endoscopist with expertise in EMR and piecemeal resection, but with limited experience in ESD.

\section{MATERIALS AND METHODS}

\section{General indications for CMI-EMR and ESD}

Generally, lesions $\geq 20 \mathrm{~mm}$ in diameter, for which en bloc resection using the conventional EMR technique is considered difficult, were the main indications for colorectal ESD or CMI-EMR. In Korea, the procedures were performed by an endoscopist (DHY) at Asan Medical Center, Seoul. DHY received training in ESD by experts at Asan Medical Center ${ }^{15}$ and performs 70-100 ESDs per year. In the United States, the procedures were performed by an endoscopist (SF) at Stanford University Hospital and VA Palo Alto, both in Palo Alto, California. SF had no clinical ESD experience at the start of the study period and received limited training through observation and performance of $<10$ procedures in an animal lab.

\section{Endoscopic submucosal dissection}

A high-definition endoscope (GIF-H260, GIF-Q260J, CF-
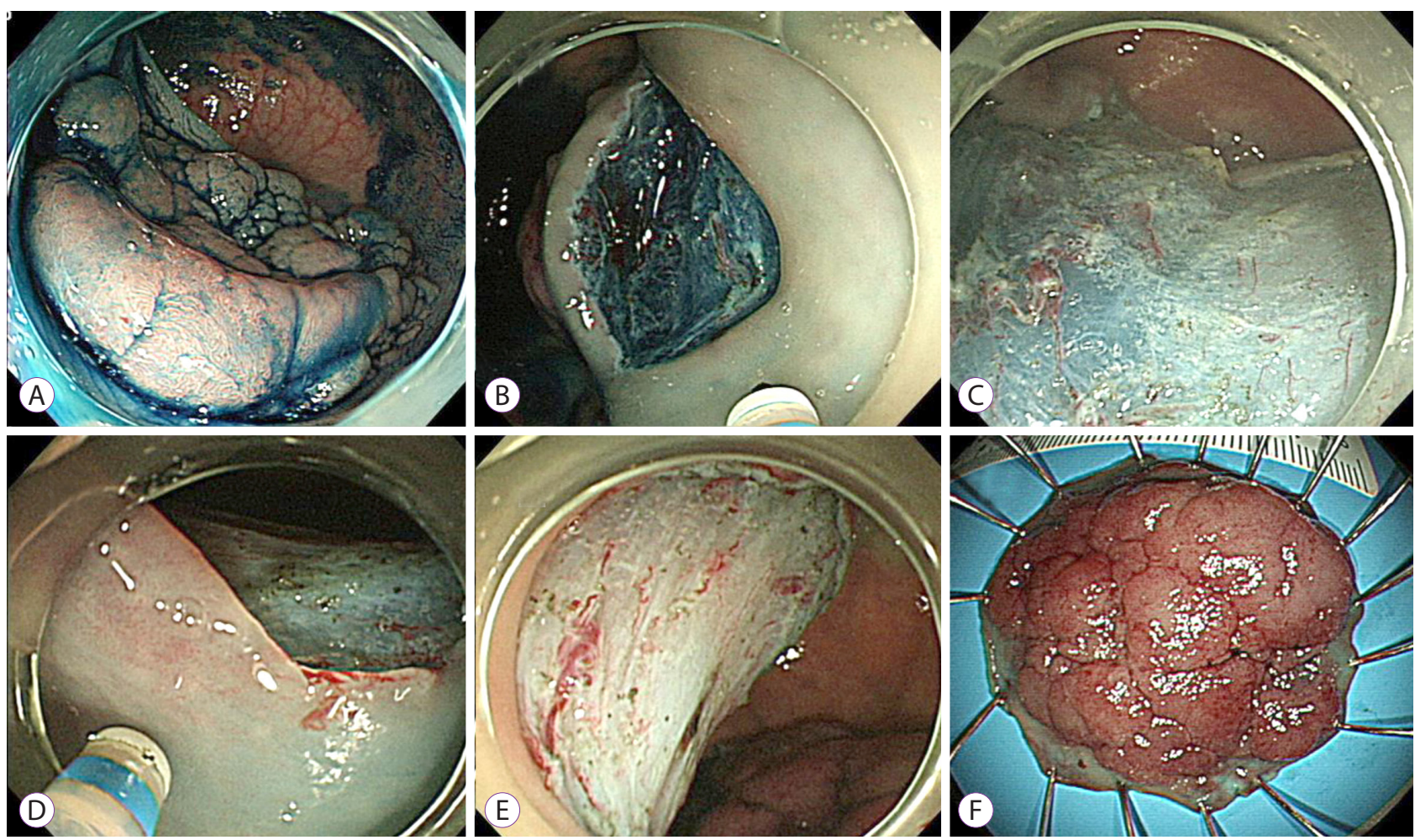

Fig. 1. Representative example of an endoscopic submucosal dissection. (A) A laterally spreading tumor on the rectum. (B) The submucosal layer was exposed after precutting and trimming. (C) An additional submucosal dissection was performed. (D) After dissecting more than $75 \%$ of the lesion, a mucosal incision was made on the oral side. The scope was retroflexed in this image. (E) A clean-based artificial ulcer remained after complete excision of the lesion. (F) The lesion was removed en bloc. 
H260AI, CF-HQ290I, or PCF-Q260AL; Olympus Co., Tokyo, Japan) or a high-definition, magnifying colonoscope (CFFH260AZI; Olympus Co.) was used for the procedures performed in Korea. An electrosurgical unit (VIO300D; ERBE, Tubingen, Germany) was used during the procedure. The main device for mucosal incision and submucosal dissection consisted of a fixed flexible snare knife (Kachu Technology Co., Seoul, Korea), a dual knife (Olympus Co.), or a hybrid knife (ERBE, Tubingen, Germany). Sodium hyaluronate solution with a small amount of indigo carmine was used for the submucosal injection in all ESD procedures. ${ }^{5}$ After careful inspection of the lesion, a submucosal cushion was created by injecting the solutions into the submucosal layer and the submucosal dissection was followed by a mucosal incision around the lesion. The details of the ESD technique have been previously described (Fig. 1). 5,15

\section{Endoscopic mucosal resection with circumferential mucosal incision}

The endoscopes used for CMI-EMR were the same as those used for ESD. The procedures performed in the United States also involved high-definition colonoscopes (Pentax EC-3490L; Pentax, Montvale, NJ, or Olympus PCF-H180; Olympus Co.,
Center Valley, PA, USA). A fixed flexible snare knife, dual knife, or the tip of the snare (Captivator ${ }^{\mathrm{TM}}$ II; Boston Scientific, Marlborough, MA, SD-230U-20; Olympus America, or Lariat $^{\mathrm{TM}}$; US Endoscopy, Mentor, OH, USA) was used for the CMI. An electrosurgical unit (VIO300D; ERBE) was used during the procedure (endocut $\mathrm{Q}$ with effect 2, cut duration 2 seconds and cut interval 6, or dry cut mode with effect 3 and $30 \mathrm{~W}$ for the mucosal incision). After meticulous endoscopic evaluation, saline mixed with methylene blue or indigo carmine was submucosally injected to lift the lesion. Epinephrine, sodium hyaluronate, ${ }^{5}$ methylcelluose, ${ }^{16,17}$ hetastarch, ${ }^{18}$ and/or $10 \%$ glycerol $^{19}$ were occasionally incorporated into the injection fluid as needed, based on the characteristics of each lesion and the availability at each institution. A circumferential incision with a 2- to 5-mm lateral safety margin was made along the peripheral rim of the lesion. Unlike in ESD and its variant procedure, hybrid $\mathrm{ESD},{ }^{20}$ little or no submucosal dissection was performed after creating a groove around the mass by a circumferential incision. An opened snare was then fitted into the groove, and the lesion was grasped as a whole. Finally, the lesion was removed using electrical currents (Fig. 2). Considering the loop diameter of each snare (SD-230U-20, $\varnothing=20$ $\mathrm{mm}$; Lariat $^{\mathrm{TM}}, \varnothing=30 \mathrm{~mm}$; Captivator $\left.{ }^{\mathrm{TM}} \mathrm{II}, \varnothing=33 \mathrm{~mm}\right), \mathrm{CMI}-$

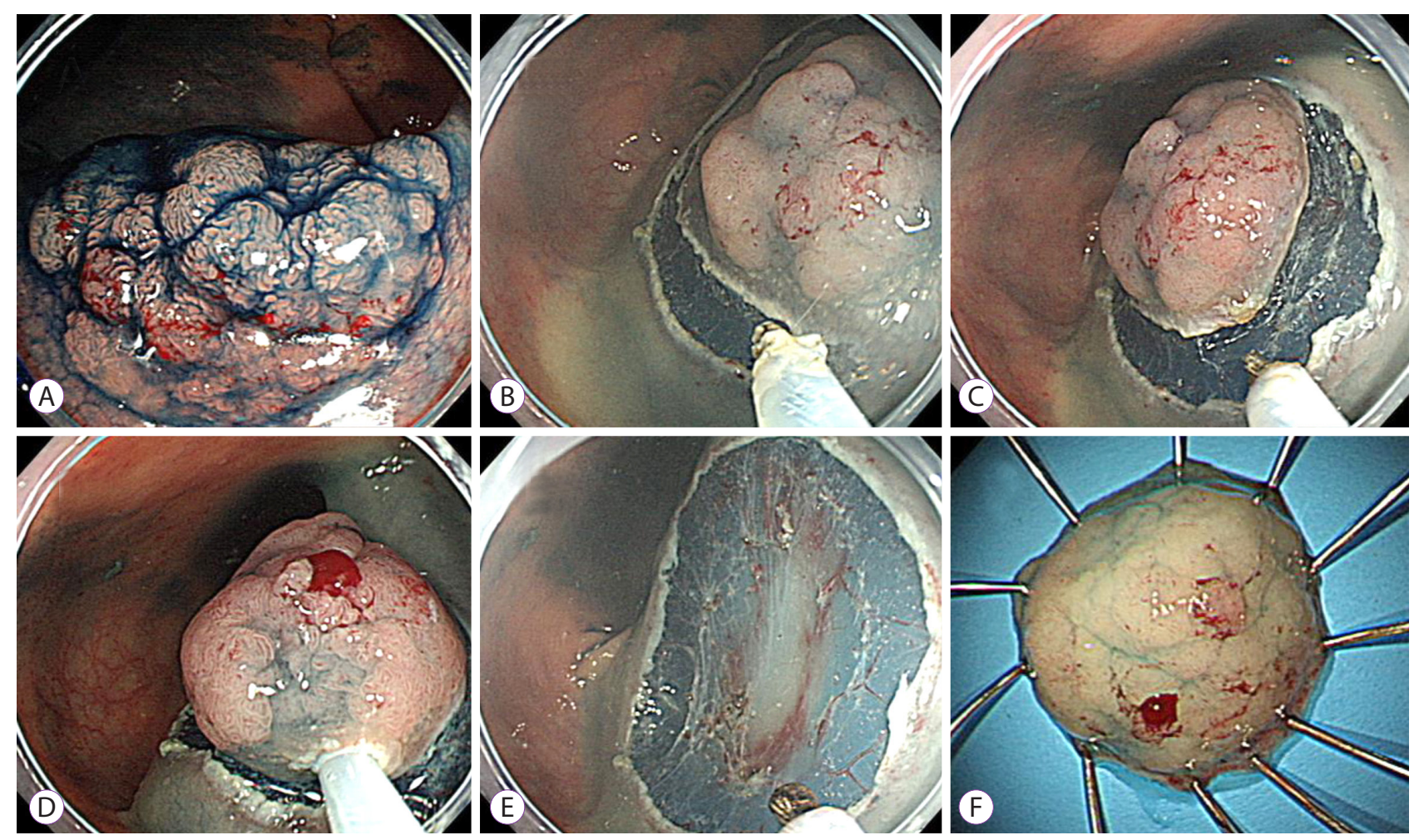

Fig. 2. Representative example of an endoscopic mucosal resection with circumferential mucosal incision. (A) A 20-mm-sized laterally spreading tumor was noted on the rectum. $(B, C)$ After submucosal injection using sodium hyaluronate solution, a circumferential mucosal incision was performed using the tip of the snare. (D, E) The lesion was snared along with the circumferential groove and resected en bloc. $(F)$ The lesion was identified as a villotubular adenoma with a high-grade dysplasia of $22 \times 18 \mathrm{~mm}$ in size. 


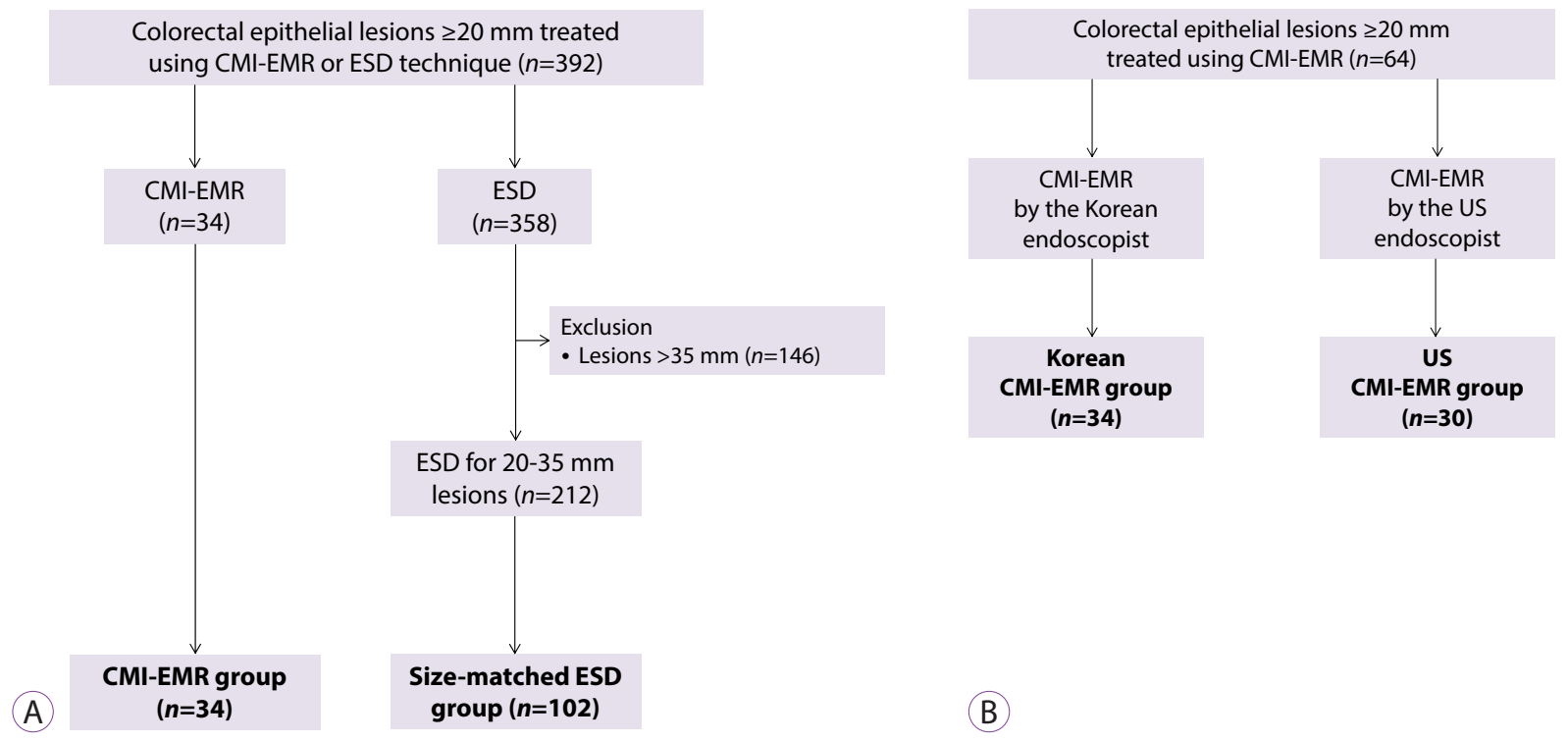

Fig. 3. Selection of cases. (A) Case selection from among the $\geq 20$-mm colorectal lesions that were removed using endoscopic mucosal resection with circumferential mucosal incision (CMI-EMR) or endoscopic submucosal dissection (ESD) at a Korean center. The size of the lesions removed using CMI-EMR ranged between 20 and $35 \mathrm{~mm}$. After excluding lesions larger than $35 \mathrm{~mm}$, size-matched ESD cases were randomly selected and matched with the CMI-EMR cases at a 1:3 ratio. (B) CMI-EMR cases performed by an experienced Korean endoscopist and an inexperienced American endoscopist were categorized as the Korean CMI-EMR group and the US CMI-EMR group, respectively.

EMR was not attempted for lesions larger than $35 \mathrm{~mm}$. In the case of eventual piecemeal resections, remnants were removed using additional hot snaring or hot biopsies.

\section{Pre-medication and procedure-related patient care}

All CMI-EMR procedures in the US were performed on outpatient basis, whereas most of the procedures in Korea, except for 2 CMI-EMR cases, were performed on inpatient basis. Prior to both procedures in Korea, $5 \mathrm{mg}$ of cimetropium bromide was administered to reduce colonic peristaltic movements, whereas no antispasmodics were administered to the patients in the United States. Antiplatelet agents were discontinued for 7 days before the procedure if the patients had no or low cardiovascular risk. Aspirin was continued in the patients with high cardiovascular risk, regardless of the procedure type. Antiplatelet agents were resumed on the next day of the procedure in the patients with low or high cardiovascular risk, provided there was no hematochezia or melena. None of the patients in these cohorts was undergoing anticoagulation therapy.

\section{Specimen histology}

Specimens in the Korean center were spread and pinned onto Styrofoam boards immediately after endoscopic resection. They were fixed in $10 \%$ buffered formalin, paraffin-embedded, cut into 2-mm-thick slices, and evaluated. Specimens in the American centers were submitted for routine histopathology in accordance with standard hospital protocols, which include neither the spreading of the specimens nor the 2-mm- thick slicing for histologic evaluation; thus, the histologic complete resection rate based on the microscopic evaluation of the resection margin was not available in the American CMI-EMR cases. Submucosal invasion of the tumor to a depth of more than $1,000 \mu \mathrm{m}$ from the muscularis mucosa was considered a deep submucosal invasive cancer.

\section{Patient selection}

From July 2010 to July 2015, a total of 392 colorectal epithelial lesions $\geq 20 \mathrm{~mm}$ in size were treated by a Korean endoscopist (DHY) by using CMI-EMR (CMI-EMR group, $n=34)$ or ESD $(n=358)$ at the Asan Medical Center in Seoul, Korea. Because the size of the CMI-EMR cases ranged from 20-35 mm, 146 ESD cases that were larger than $35 \mathrm{~mm}$ were excluded. Then, size-matched ( $\pm 3 \mathrm{~mm}$ ) lesions were randomly recruited at a 1:3 ratio as comparative controls of the CMIEMR cases (size-matched ESD group) (Fig. 3). From Sept 2012 to July 2015, 5 ESDs and 30 CMI-EMRs were performed by an American endoscopist (SF) for colorectal epithelial lesions $\geq 20 \mathrm{~mm}$ in size at Stanford Hospital or at the Veterans Administration Palo Alto Healthcare System in California. For comparison, the CMI-EMR cases performed by the Korean and American endoscopist were categorized as the Korean CMI-EMR group ( $n=34$ ) and the US CMI-EMR group $(n=30)$, respectively (Fig. 3). Five ESD cases performed by the American endoscopist were not included in the analysis because of the small number of cases and different level of experience in ESD compared with that of the Korean endoscopist. 


\section{Data collection}

All medical records were reviewed. Procedure-related outcomes including procedure time, en bloc resection rate, histologic complete resection rate, and adverse events were retrieved. The right colon was defined as the splenic flexure and the more proximal portions of the colon. The left colon was defined as the sigmoid colon and the descending colon up to but not including the splenic flexure. Local recurrence was evaluated when surveillance endoscopy was performed. All procedures were performed with informed consent. This retrospective case-control study was approved by the institutional review boards of the Asan Medical Center, the Stanford University School of Medicine, and the Veterans Administration Palo Alto Healthcare System.

\section{Statistical analysis}

To assess the efficacy and safety of CMI-EMR relative to ESD, the procedure-related outcomes of the CMI-EMR and size-matched ESD groups were compared. Differences between CMI-EMRs performed by the Korean and the American endoscopist were also analyzed. Comparisons of continuous variables were performed using the Student's $t$-test. Dichotomous or categorical variables were compared using the chi-square test or Fisher's exact test. A $p$-value $<0.05$ was considered statistically significant. Statistical analysis was performed with SPSS version 21.0 for Windows software (SPSS Inc., Chicago, IL, USA).

\section{RESULTS}

\section{Comparison between the CMI-EMR and ESD cases treated by a Korean endoscopist}

Baseline characteristics and procedure-related outcomes of the CMI-EMR and size-matched ESD cases treated by a Korean endoscopist are provided in Tables 1 and 2. There

Table 1. Baseline Characteristics of CMI-EMR and Size-Matched ESD Cases Treated by a Korean Endoscopist

\begin{tabular}{|c|c|c|c|}
\hline Variables & $\begin{array}{c}\text { CMI-EMR group } \\
\text { (34 lesions in } 34 \text { patients) }\end{array}$ & $\begin{array}{l}\text { Size-matched ESD group } \\
\left(102 \text { lesions in } 100 \text { patients }^{\mathrm{a})}\right)\end{array}$ & $p$-value \\
\hline Age, yr, mean $\pm S D$ & $61.6 \pm 8.0$ & $62.2 \pm 10.1$ & 0.730 \\
\hline Sex, male, $n(\%)$ & $18(52.9)$ & $61(59.8)$ & 0.482 \\
\hline Antiplatelet agents ${ }^{\mathrm{b})}, n(\%)$ & $1(2.9)$ & $1(1.0)$ & 0.439 \\
\hline Coagulopathy, $n$ (\%) & 0 & 0 & NA \\
\hline Thrombocytopenia $^{c)}, n(\%)$ & $1(2.9)$ & 0 & 0.250 \\
\hline Size, $\mathrm{mm}$, mean $\pm \mathrm{SD}$ & $22.3 \pm 3.9$ & $22.9 \pm 2.4$ & 0.268 \\
\hline Location $^{\mathrm{d})}, n(\%)$ & & & 0.289 \\
\hline Right colon & $19(55.9)$ & $45(44.1)$ & \\
\hline Left colon & $8(23.5)$ & $21(20.6)$ & \\
\hline Rectum & $7(20.6)$ & $36(35.3)$ & \\
\hline Morphology, $n(\%)$ & & & 0.999 \\
\hline Is & $4(11.8)$ & $13(12.7)$ & \\
\hline II (IIa, IIb, or IIa + IIc) & $30(88.2)$ & $89(87.3)$ & \\
\hline Histology, $n(\%)$ & & & 0.258 \\
\hline TA, TVA, or VA & $28(82.4)$ & $81(79.4)$ & \\
\hline $\mathrm{SSA} / \mathrm{P}$ & $5(14.7)$ & $6(5.9)$ & \\
\hline Superficial submucosal cancer & $1(2.9)$ & $8(7.8)$ & \\
\hline Deep submucosal cancer & 0 & $6(5.9)$ & \\
\hline Non-neoplastic lesions & 0 & $1(1.0)$ & \\
\hline
\end{tabular}

CMI-EMR, endoscopic mucosal resection with circumferential mucosal incision; ESD, endoscopic submucosal dissection; SD, standard deviation; NA, not applicable; TA, tubular adenoma; TVA, tubulovillous adenoma; VA, villous adenoma; SSA/P, sessile serrated adenoma/polyps.

${ }^{a)}$ Two patients had 2 synchronous lesions which were removed by using ESD technique.

${ }^{\text {b) }}$ Continued antiplatelet medication until the procedure date or $<7$ days before the procedure.

${ }^{c}$ Platelet count $<80 \times 10^{3} / \mathrm{mm}^{3}$.

${ }^{\text {d) }}$ Right colon was defined as the splenic flexure and the more proximal portions of the colon. Left colon was defined as the sigmoid colon and descending colon. 
Table 2. Procedure-Related Variables of CMI-EMR and Size-Matched ESD Cases Treated by a Korean Endoscopist

\begin{tabular}{|c|c|c|c|}
\hline Variables & $\begin{array}{l}\text { CMI-EMR group } \\
\text { (34 lesions) }\end{array}$ & $\begin{array}{c}\text { Size-matched ESD group } \\
\text { (102 lesions) }\end{array}$ & $p$-value \\
\hline Device for mucosal incision & & & $<0.001$ \\
\hline Endoknife & $11(32.4)$ & $102(100)$ & \\
\hline Tip of snare & $23(67.6)$ & 0 & \\
\hline Submucosal injection solution, $n(\%)$ & & & $<0.001$ \\
\hline Saline-based solution only & $12(35.3)$ & 0 & \\
\hline Sodium hyaluronate & $22(64.7)$ & $102(100)$ & \\
\hline Resection time, minutes, mean $\pm \mathrm{SD}$ & $12.7 \pm 7.0$ & $45.6 \pm 30.1$ & $<0.001$ \\
\hline Gross en bloc resection, $n(\%)$ & $32(94.1)$ & $102(100)$ & 0.061 \\
\hline Histologic complete resection, $n(\%)$ & $26(76.5)$ & $92(90.2)$ & 0.075 \\
\hline \multicolumn{4}{|l|}{ Complications } \\
\hline Postprocedural hemorrhage, $n(\%)$ & $1(2.9)$ & $1(1.0)$ & 0.439 \\
\hline Perforation, $n(\%)$ & $2(5.9)$ & $3(2.9)$ & 0.599 \\
\hline
\end{tabular}

CMI-EMR, endoscopic mucosal resection with circumferential mucosal incision; ESD, endoscopic submucosal dissection; SD, standard deviation.

Table 3. Baseline Characteristics of CMI-EMR Cases That Were Performed by a Korean and an American Endoscopist

\begin{tabular}{|c|c|c|c|}
\hline Variables & $\begin{array}{l}\text { Korean CMI-EMR group } \\
\qquad(n=34)\end{array}$ & $\begin{array}{l}\text { US CMI-EMR group } \\
\qquad(n=30)\end{array}$ & $p$-value \\
\hline Age, yr, mean $\pm S D$ & $61.6 \pm 8.0$ & $67.6 \pm 7.9$ & 0.004 \\
\hline Sex, male, $n(\%)$ & $18(52.9)$ & $21(70)$ & 0.163 \\
\hline Antiplatelet agents ${ }^{\mathrm{a})}, n(\%)$ & $1(2.9)$ & $7(23.3)$ & 0.021 \\
\hline Coagulopathy, $n(\%)$ & 0 & 0 & NA \\
\hline Thrombocytopenia $^{\text {b) }}, n(\%)$ & $1(2.9)$ & 0 & 0.999 \\
\hline Size, $\mathrm{mm}, \mathrm{mean} \pm \mathrm{SD}$ & $22.3 \pm 3.4$ & $23.2 \pm 4.7$ & 0.405 \\
\hline Location $^{c)}, n(\%)$ & & & 0.331 \\
\hline Right colon & $19(55.9)$ & $21(70)$ & \\
\hline Left colon & $8(23.5)$ & $3(10)$ & \\
\hline Rectum & $7(20.6)$ & $6(20)$ & \\
\hline Morphology, $n(\%)$ & & & 0.495 \\
\hline Is & $4(11.8)$ & $6(20)$ & \\
\hline II (IIa, IIb, or IIa + IIc) & $30(88.2)$ & $24(80)$ & \\
\hline Histology, $n(\%)$ & & & 0.604 \\
\hline TA, TVA, or VA & $28(82.4)$ & $21(70)$ & \\
\hline SSA/P & $5(14.7)$ & $8(26.7)$ & \\
\hline Superficial submucosal cancer & $1(2.9)$ & $1(3.3)$ & \\
\hline
\end{tabular}

CMI-EMR, endoscopic mucosal resection with circumferential mucosal incision; SD, standard deviation; NA, not applicable; TA, tubular adenoma; TVA, tubulovillous adenoma; VA, villous adenoma; SSA/P, sessile serrated adenoma/polyps.

${ }^{a}$ Continued antiplatelet medication until the procedure date or $<7$ days before the procedure.

${ }^{\text {b) }}$ Platelet count $<80 \times 10^{3} / \mathrm{mm}^{3}$.

${ }^{c}$ Right colon was defined as the splenic flexure and the more proximal portions of the colon. Left colon was defined as the sigmoid colon and descending colon.

were no significant differences in age or sex between the two groups. The lesion sizes were $22.3 \pm 3.9 \mathrm{~mm}$ (range, 20-35) and $22.9 \pm 2.4 \mathrm{~mm}$ (range, 20-35) in the CMI-EMR and size- matched ESD groups, respectively $(p=0.268)$.

The resection time was significantly shorter in the CMIEMR group than in the size-matched ESD group (12.7 \pm 7.0 
Table 4. Procedure-Related Variables of CMI-EMR Cases Performed by a Korean and an American Endoscopist

\begin{tabular}{|c|c|c|c|}
\hline Variables & $\begin{array}{l}\text { Korean CMI-EMR group } \\
\qquad(n=34)\end{array}$ & $\begin{array}{l}\text { US CMI-EMR group } \\
\qquad(n=30)\end{array}$ & $p$-value \\
\hline Device for CMI-EMR or ESD, $n(\%)$ & & & $<0.001$ \\
\hline Endoknife & $11(32.4)$ & $27(90)$ & \\
\hline Tip of snare & $23(67.6)$ & $3(10)$ & \\
\hline Submucosal injection solution, $n(\%)$ & & & $<0.001$ \\
\hline Saline-based solution only & $12(35.3)$ & $23(76.7)$ & \\
\hline Adjuvant solution ${ }^{\text {a) }}$ & $22(64.7)$ & $7(23.3)$ & \\
\hline Resection time, minutes, mean $\pm \mathrm{SD}$ & $12.7 \pm 7.0$ & $18.7 \pm 11.3$ & 0.011 \\
\hline Gross en bloc resection, $n(\%)$ & $32(94.1)$ & $24(80)$ & 0.133 \\
\hline Histologic complete resection, $n(\%)$ & $26(76.5)$ & $\mathrm{NA}^{\mathrm{b})}$ & NA \\
\hline \multicolumn{4}{|l|}{ Complications } \\
\hline Postprocedural hemorrhage, $n(\%)$ & $1(2.9)$ & 0 & 0.999 \\
\hline Perforation, $n(\%)$ & $2(5.9)$ & 0 & 0.494 \\
\hline
\end{tabular}

CMI-EMR, endoscopic mucosal resection with circumferential mucosal incision; ESD, endoscopic submucosal dissection; SD, standard deviation; NA, not applicable.

a) Adjuvant solution indicates the use of sodium hyaluronate, methylcelluose, hetastarch, and/or 10\% glycerol.

${ }^{b}$ Specimens of American cases were submitted for routine histopathology in accordance with standard hospital protocols, which include neither spreading of the specimens nor $2 \mathrm{~mm}$-thick slicing for histologic evaluation, and thus the histologic complete resection rate based on the microscopic evaluation of the resection margin was not available.

min vs. $45.6 \pm 30.1 \mathrm{~min}, p<0.001)$. The CMI-EMR group showed a tendency toward lower en bloc resection and histologic complete resection rates than the size-matched ESD group. All cases of piecemeal resection in the CMI-EMR group involved mucosal lesions, such as tubular adenoma (TA), tubulovillous adenoma (TVA), villous adenoma (VA), or sessile serrated adenoma/polyps (SSA/P). There were no differences in terms of postprocedural hemorrhage or perforation between the two groups. All perforations were successfully treated without surgery.

Surveillance endoscopy was performed in 21 (61.8\%) of 34 patients in the Korean CMI-EMR group, with a median follow-up of 13.8 months (range, 2.5-39.1) and in 70 (68.6\%) of 102 patients in the size-matched ESD group, with a median follow-up of 13.5 months (range, 0.9-50.6). There was no recurrence during surveillance in either group.

\section{Comparison between the Korean CMI-EMR and US CMI-EMR groups}

The mean age of the patients was older in the US CMIEMR group than in the Korean CMI-EMR group. Continuation of the antiplatelet agents during the procedure was more common in the US CMI-EMR group than in the Korean CMI-EMR group. Variables related to lesion characteristics were not different between the two groups (Table 3). Resection time was significantly shorter in the Korean group than in the US group (12.7 $\pm 7.0 \mathrm{~min}$ vs. $18.7 \pm 11.3 \mathrm{~min}$, respectively, $p=0.011)$. The en bloc resection rate was not statistically different between the groups ( $94.1 \%$ in the Korean CMI-EMR group and $80 \%$ in the US CMI-EMR group; $p=0.133$ ). One postprocedural hemorrhage and two perforations occurred in the Korean CMI-EMR group, while there were no procedure-related adverse events in the US CMI-EMR group; however, the difference in the frequency of procedure-related adverse events was not significant between the two groups. Procedure-related outcomes are presented in Table 4. Surveillance endoscopy was performed in 21 (61.8\%) of 34 patients in the Korean CMI-EMR group, with a median follow-up of 13.8 months (range, 6.1-39.1), and in 9 (30\%) of 30 patients in the US CMI-EMR group, with a median follow-up of 9.4 months (range, 2.5-21.2). There was no recurrence in either group.

\section{DISCUSSION}

In our present study, we compared CMI-EMR and sizematched ESD for the resection of colorectal neoplasms with a diameter of 20-35 $\mathrm{mm}$. The en bloc resection rate of the CMIEMR group was comparable to that of the size-matched ESD group (94.1\% vs. 100\%). All of the piecemeal resection cases in the CMI-EMR groups were mucosal lesions, such as TA, TVA, VA, or SSA/P, for which piecemeal resection could be justified as a treatment option. Moreover, CMI-EMR required significantly less resection time than ESD (12.7 \pm 7.0 minutes vs. 
45.6 \pm 30.1 minutes, respectively), and there was no difference in the rate of adverse events, such as postprocedural hemorrhage and perforation. Although no recurrences were found in either group, the follow-up duration was not sufficient to provide any conclusion about the difference in the recurrence rate between CMI-EMR and ESD. Nonetheless, considering the technical difficulty and longer procedure time for colorectal ESD, CMI-EMR may still be preferable, if the invasive cancers can be effectively excluded before endoscopic resection.

We consider that CMI-EMR is essentially a variation of the conventional EMR technique designed to achieve en bloc resection by making a circumferential groove that prevents the snare from slipping. ${ }^{7}$ Because little or no submucosal dissection is required to make the circumferential groove, ${ }^{21} \mathrm{CMI}-$ EMR is technically easier to perform than ESD and saves time by avoiding the trimming and submucosal dissection phases of ESD. Accordingly, CMI-EMR may provide acceptable procedure-related outcomes even if it is performed by an endoscopist with limited colorectal ESD experience. To explore this issue, we compared the outcomes of CMI-EMRs performed by an experienced Korean endoscopist (Korean CMI-EMR group) and those performed by an inexperienced American endoscopist (US CMI-EMR group). The procedure time in the US CMI-EMR group was significantly longer than that in the Korean CMI-EMR group. The gross en bloc resection rate and complication rate were not statistically different between these two groups, with a slight trend towards a lower en bloc rate and fewer complications in the US group. This suggests that extensive ESD experience is not necessary to achieve excellent results with CMI-EMR. The en bloc resection rates of CMIEMR ( $80 \%$ in the US group and $94 \%$ in the Korean group) were favorable when compared with the reported en bloc resection rates of $53.5 \%-57.5 \%$ for $23-25 \mathrm{~mm}$-colorectal polyps, using conventional EMR. ${ }^{22,23}$

Our study had several limitations. First, retrospective data from only two endoscopists with different experience levels were used in the analysis, and the number of cases was too small to discern subtle differences between the groups. Other potential biases, including the selection of cases for CMIEMR, should also be considered when interpreting our results. Additional factors that can potentially affect en bloc resection and procedure times, such as submucosal fibrosis, redundancy of the colon, types of submucosal injection solutions, and bowel preparation quality, were not available or could not be investigated in sufficient detail in our analysis. Third, potential differences in the clinical situation at each center could not be analyzed. For example, all the procedures used in the Korean CMI-EMR $\geq 20 \mathrm{~mm}$ and ESD groups were performed in an inpatient setting, whereas all those of the US CMI-EMR group were performed in an outpatient setting. The endosco- pist may be more cautious of adverse events in an outpatient setting, and thus may sometimes prefer piecemeal over en bloc resection to minimize the risk of perforation. In addition, the lack of rigorous histopathological specimen processing in American centers made it impossible to assess the histologic thoroughness of the resection as was done for the Korean data.

In conclusion, CMI-EMR for colorectal neoplasia 20-35 $\mathrm{mm}$ in size yields an excellent en bloc resection rate. Although CMI-EMR showed a trend toward lower en bloc resection rate than ESD, it has the advantage of shorter procedure time. Moreover, a Western endoscopist with limited experience in colorectal ESD performed CMI-EMR safely and achieved an en bloc resection rate comparable to that achieved by a Korean ESD expert, suggesting that expertise in ESD is not required for achieving appropriate clinical outcomes with CMI-EMR.

\section{Conflicts of Interest}

The authors have no financial conflicts of interest.

\section{REFERENCES}

1. Saito Y, Fukuzawa M, Matsuda T, et al. Clinical outcome of endoscopic submucosal dissection versus endoscopic mucosal resection of large colorectal tumors as determined by curative resection. Surg Endosc 2010;24:343-352.

2. Kobayashi N, Yoshitake N, Hirahara Y, et al. Matched case-control study comparing endoscopic submucosal dissection and endoscopic mucosal resection for colorectal tumors. J Gastroenterol Hepatol 2012;27:728733.

3. Terasaki M, Tanaka S, Oka S, et al. Clinical outcomes of endoscopic submucosal dissection and endoscopic mucosal resection for laterally spreading tumors larger than $20 \mathrm{~mm}$. J Gastroenterol Hepatol 2012;27:734-740.

4. Saito Y, Uraoka T, Yamaguchi Y, et al. A prospective, multicenter study of 1111 colorectal endoscopic submucosal dissections (with video). Gastrointest Endosc 2010;72:1217-1225.

5. Byeon JS, Yang DH, Kim KJ, et al. Endoscopic submucosal dissection with or without snaring for colorectal neoplasms. Gastrointest Endosc 2011;74:1075-1083.

6. Lee EJ, Lee JB, Choi YS, et al. Clinical risk factors for perforation during endoscopic submucosal dissection (ESD) for large-sized, nonpedunculated colorectal tumors. Surg Endosc 2012;26:1587-1594.

7. Hirao M, Masuda K, Asanuma T, et al. Endoscopic resection of early gastric cancer and other tumors with local injection of hypertonic saline-epinephrine. Gastrointest Endosc 1988;34:264-269.

8. Kim JJ, Lee JH, Jung HY, et al. EMR for early gastric cancer in Korea: a multicenter retrospective study. Gastrointest Endosc 2007;66:693-700.

9. Cai S, Zhong Y, Zhou P, Xu J, Yao L. Re-evaluation of indications and outcomes of endoscopic excision procedures for colorectal tumors: a review. Gastroenterol Rep (Oxf) 2014;2:27-36.

10. Min BH, Lee JH, Kim JJ, et al. Clinical outcomes of endoscopic submucosal dissection (ESD) for treating early gastric cancer: comparison with endoscopic mucosal resection after circumferential precutting (EMR-P). Dig Liver Dis 2009;41:201-209.

11. Huang J, Lu ZS, Yang YS, et al. Endoscopic mucosal resection with circumferential incision for treatment of rectal carcinoid tumours. World J Surg Oncol 2014;12:23. 
12. Sakamoto T, Matsuda T, Nakajima T, Saito Y. Efficacy of endoscopic mucosal resection with circumferential incision for patients with large colorectal tumors. Clin Gastroenterol Hepatol 2012;10:22-26.

13. Lee EJ, Lee JB, Lee SH, Youk EG. Endoscopic treatment of large colorectal tumors: comparison of endoscopic mucosal resection, endoscopic mucosal resection-precutting, and endoscopic submucosal dissection. Surg Endosc 2012;26:2220-2230.

14. Hong YM, Kim HW, Park SB, Choi CW, Kang DH. Endoscopic mucosal resection with circumferential incision for the treatment of large sessile polyps and laterally spreading tumors of the colorectum. Clin Endosc 2015;48:52-58.

15. Yang DH, Jeong GH, Song Y, et al. The feasibility of performing colorectal endoscopic submucosal dissection without previous experience in performing gastric endoscopic submucosal dissection. Dig Dis Sci 2015;60:3431-3441.

16. Feitoza AB, Gostout CJ, Burgart LJ, Burkert A, Herman LJ, Rajan E. Hydroxypropyl methylcellulose: a better submucosal fluid cushion for endoscopic mucosal resection. Gastrointest Endosc 2003;57:41-47.

17. Hyun JJ, Chun HR, Chun HJ, et al. Comparison of the characteristics of submucosal injection solutions used in endoscopic mucosal resection. Scand J Gastroenterol 2006;41:488-492.
18. Fasoulas K, Lazaraki G, Chatzimavroudis G, et al. Endoscopic mucosal resection of giant laterally spreading tumors with submucosal injection of hydroxyethyl starch: comparative study with normal saline solution. Surg Laparosc Endosc Percutan Tech 2012;22:272-278.

19. Fujishiro M, Yahagi N, Nakamura M, et al. Successful outcomes of a novel endoscopic treatment for GI tumors: endoscopic submucosal dissection with a mixture of high-molecular-weight hyaluronic acid, glycerin, and sugar. Gastrointest Endosc 2006;63:243-249.

20. Toyonaga T, Man-I M, Morita Y, Azuma T. Endoscopic submucosal dissection (ESD) versus simplified/hybrid ESD. Gastrointest Endosc Clin N Am 2014;24:191-199.

21. Tanaka S, Kashida H, Saito Y, et al. JGES guidelines for colorectal endoscopic submucosal dissection/endoscopic mucosal resection. Dig Endosc 2015;27:417-434.

22. Buchner AM, Guarner-Argente C, Ginsberg GG. Outcomes of EMR of defiant colorectal lesions directed to an endoscopy referral center. Gastrointest Endosc 2012;76:255-263.

23. Luigiano C, Consolo P, Scaffidi MG, et al. Endoscopic mucosal resection for large and giant sessile and flat colorectal polyps: a single-center experience with long-term follow-up. Endoscopy 2009;41:829-835. 